\title{
Research Analysis on Barriers to Green Supply Chain Management in Pharmaceutical Industries
}

\author{
Muhammad Faisal* \\ Institute of Business Management (IoBM), Korangi Creek, Karachi-75190, Pakistan
}

\begin{abstract}
This paper describes the behaviour related to the barriers green supply chain management with respect to pharmaceutical companies in Karachi. Responses have been signature after collection of their genuine response with respect to barriers in green supply chain Tests have been divided in various constructs, named cost, training, management, government concerns, awareness, knowledge, legislation, SOPS, competitor, region which has been label according to their nature. This study is related to the barriers or hurdles in the implementation of the green supply Chain Management. Pharmaceutical industry is trying to implement green environment but due to some factors indicated in this study they are unable to portray the green environment. This study is covering almost all aspects that indicate green supply chain management barriers. The instrument is being developed on the basis of literature review which is covering almost all the external and internal drivers. The internal and external drivers include some organizational related factors, like top management, resources, trainings, professionalism. Some external factors also include resources, TQEM (Total quality environmental management) and awareness. Barriers in the implementation of the green supply chain management are both internal and external. To reveal the actual truth behind the implementation of green environment we conducted study by running exploratory factor analysis and confirmatory factor analysis. Designed an instrument and conducted the interviews of the persons revealing the hurdles in the implementation of the green environment. Respondents will be answering the questions of the instrument and their data has been recorded. The number of constructs is six in this instrument with 38 variables. Data of respondents is collected from the pharmaceutical organizations of supply chain professionalism. This research has been conducted in various pharmaceutical
\end{abstract}

Companies of Pakistan including Abbot, GSK, Getz pharmaceutical etc. KMO and Bartlett as test, this test scored significance level.

Keywords: Pharmaceutical; Green supply chain management; Validity; Barriers; Green environment; Sample size

\section{Introduction}

This research is to conduct Barrier to implement Green supply chain management in pharmaceutical industries in Karachi. Variables are analysed such as Cost: green design, green manufacturing, green labelling of packing etc. are too high. Organizations are trying to save cost by utilizing the non-green methodologies. Cost of environment friendly goods and packaging is very high. Slow return of investments on GSCM. Training: Lack of training and education of employees about GSCM, No institutional support, awareness and trainings from the government side Awareness: Lack of consumer awareness produces, less pressure and support towards the implementation of green supply chain, Due to unawareness of customer, stake holders and suppliers and due to non-commitment of top management, Due to lack of awareness the investors and shareholders are unable to pressure organization to implement GSCM. Unawareness of the consumer towards green environment. Knowledge: Lack of knowledge among organizational stake holders, Lack of knowledge of the vendors, suppliers about GSCM, Suppliers are lacking the knowledge about the destructive consequences of their product on the environment, Suppliers are lacking the knowledge about the destructive consequences of their product on the environment. Legislations: Thus, lack of Environmental concerns and legislation, Lack of professionalism and legislations, No regulatory guidelines for the management of environment by GSCM. SOPS: Lacking in the SOPS of human resource to develop the GSCM. Competitors: Market competition for the generics is an important, Due to traditional mind-set about the fear of failure. Lack of resources to approach global marketing, cost of environment friendly goods and packaging is very high. Resources: Lack of resources to approach global marketing, Due to lack of resources in industries for proper recycling,
Due to lack of resources in industries for proper recycling. Region: Lack of green architects, consultants, green developers, contractors in the region, there is no bank loans available in the region for the industries to implement green practices, the pressure on timely delivery of product in the region, as there is no market for the recycled products in the region, Due to the lack of internal audits within the organization [1].

\section{Executive summary}

$70 \%$ respondents were males and $30 \%$ were females. The total frequency of the respondents was 60 . Basic aim is to reduce cost, provide effective training standard procedures to implement green supply chain industry in Karachi, aware public about green supply chain and to make this purpose more effective and beneficial in order to ensure healthy environment, providing internal audits and standard operating procedures in order to minimize barriers in green supply chain, proper recycling should be done, training and awareness program launch, regions in which supply chain is distributed and to implement technology train motive and aware them in order to maintain friendly green environment.

*Corresponding author: Faisal Md, Assistant Professor, Institute of Business Management (loBM), Korangi Creek, Karachi-75190, Pakistan, Tel: +92213509096167; E-mail: std_16743@iobm.edu.pk

Received November 02, 2015; Accepted November 26, 2015; Published November 28, 2015

Citation: Faisal M (2015) Research Analysis on Barriers to Green Supply Chain Management in Pharmaceutical Industries. Review Pub Administration Manag 3 : 176. doi: $10.4172 / 2315-7844.1000176$

Copyright: (c) 2015 Faisal M. This is an open-access article distributed under the terms of the Creative Commons Attribution License, which permits unrestricted use, distribution, and reproduction in any medium, provided the original author and source are credited. 


\section{Literature review}

Every question of the instrument is developed on the basis of literature review. Green supply chain management scope is very large and is not confined to simple supply chain process. Green supply chain management escalating the use of harmful material. Green Supply chain Management is concentrating towards environment friendly goods including from raw material till the finished product. In the implementation of the green environment Cost is very important factor because the initial investment requires establishing the green methodologies are very high and this includes green manufacturing facility, green packaging, and carbon free environment. The cost for this would be very high. The cost is not only related to the establishment but also includes the cost on equipment, trainings. After this investment the company would be looking for large revenue but in this regard the revenue is not as higher as the investment. Education and training of employees requires trained personals on Green supply chain management so ultimately the country lacks those experts of green supply chain management who could trained the employees but the available trainers asking for a huge amount and the company is not eager to waste the money in GSCM because they know the slow return of the investment and may be the return wouldn't take place. Employees are not only confined to the training because supplier is also the person responsible to provide some intermediates and raw materials to manufacturer of finish product. Training of supplier also counts in this regard. If the supplier will know the proper disposable or will know the green environment goods so will be able to produce green environment. Top management has a more powerful role in the implementation of green environment because top management is covering all the expenses of the industry. Top management is designing the budget of the company. Top management is inducting the trainings of the employees and consumers through different awareness sessions and programs and some promotional activities [2].

Pharmaceutical companies have very stringent guidelines, regulations. They have acts which must be followed in order to continue the license manufacturing. But the guidelines related to the green supply chain implementation in pharmaceutical are over looked in the forensic pharmacy.

To produce the green environment it has been recommended that all the wastage of the industries will be drained from some GMP drainers where the waste will be neutralize means the waste will becoming nonhazardous. This will prevent environmental damaging. Green supply chain management is referring to as a variety of activities and initiatives passed by an organization in order to lessen their impact on the natural environment (Awaysheh and Klassen). The Green supply chain management practices include: 2.3.1 Reverse Logistics is a process to do plan, implement and control the efficient, effective go of raw materials, in process material, finished products and relevant knowledge from the point of consumption to the point and after disposing the raw material. It is the responsibility of the pharmaceutical companies in Karachi to develop the reverse logistics networks and flow of options in order to refrain from the dissatisfaction of the customers and return of outsourced drugs [3].

Today green supply chain Management has become a really hot topic among pharmaceuticals. All the pharmaceuticals utilizing chemicals and there by product is hazardous which is damaging to the environment. The implementation of green supply chain management has become a necessity to prevent from environmental damage. Pharmaceutical companies are growing day by day but they have low positive attitude towards environment. Pharmaceutical companies are seeking for an alternative to establish a green environment by planting trees. The definition and scope of GSCM in the literature has ranged from green purchasing to integrated green supply chains flowing from supplier to manufacturer to customer.

To advance investigation and practice in GSCM, appropriate measurement scales are needed. In general, identification of appropriate measurement scales for emerging concepts and theories is necessary to complete robust research and to advance the body of knowledge in a field. The field of GSCM is arguably in its early development phases, both academically and practically. Academically, to effectively and empirically advance theory within this field, some useful and testable multi-item measurement scales are needed. Using literature in supply chain (operations) and environmental management, we introduce a number of scales that may be used to help evaluate practices in this area. Practically, organizations can also benefit from development of reliable and valid scales to measure GSCM practices implementation. Practitioners can use these scales for benchmarking, continuous improvement and project management activities when seeking to implement GSCM practices. One contribution of this study is to help manufacturers understand the different facets of GSCM practices implementation and identify the strengths and weaknesses of the implementation of their GSCM practices. Given the academic (theoretical) and practical importance of developing a GSCM practices implementation measurement scale, we introduce a study based on an empirical survey of Pharmaceutical Companies. In some ways they are very advanced in practices and technology due to their relationships with international partners and community. The objective of this study is to investigate the GSCM practice implementation construct and its defining measurement items emphasizing Pharmaceutical companies with broader implications for application of these scales to other environments. In this paper we initially introduce literature reviews of measurement items for GSCM implementation [4].

Institutional Pressures (IP) - Recent years have seen an increasing role of institutional theory in the fields of OM and SCM (Kauppi). According to Scott, institutional theory suggests that external forces motivate firms to undertake similar strategic actions. Under institutional theory, firms are not only profit-seeking entities, but also recognize the importance of achieving social legitimacy. Institutional theory has two main forms, an economic variant and a social variant (Ketokivi and Schroeder). The mechanisms identified are coercive, mimetic and normative, which lead towards institutional isomorphism (DiMaggio and Powell). The coercive mechanism consists of formal or informal pressures created on firms by other firms on which they are dependent and by expectations from society (Kauppi 2013; DiMaggio and Powell). For example, government regulations play a crucial role in adjusting supply chain activities to be greener. ISO 14001 certification helps organizations to improve their existing environmental standard and waste reduction. Emission norms set by government regulate the emission limits of both petrol and diesel engines to protect the environment against emission of excess carbon content into the atmosphere. More stringent norms are needed though to regulate the increasing issue of global warming. Many organizations involved in exports have started adopting the green practices in their supply chain as part of the competition with foreign domestic players. The marketing strategies have also begun to showcase them as environmentallyfriendly organizations to gain customer attention. Zhu et al. argued the role of institutions in the successful implementation of GSCM practices. Dubey et al. have further argued the moderating role played by institutional pressures on SRM and TQM, which help enhance environmental performance. 
Top management commitment (TMC): Top management commitment is vital to organizations and supply chain partners aiming to implement green and sustainable practices (Liang et al.; Gattiker and Carter; Foerstl et al.). The importance of top management beliefs, practices, and commitment has been hence highlighted in the literature (Abdulrahman et al.; Bag and Anand; Jabbour and Jabbour). Hence, without support from higher management it is impossible to make use of cleaner and greener resources in the supply chain. Management should be proactive rather than reactive in going green in every aspect possible. Recent research supports our assumption that top management commitment is an important enabler (Deif; Despeisse et al.; Law and Gunasekaran; Singh et al.; Dues et al.; Hoof and Lyon; Dubey et al.).

Reduction in carbon emissions (RCE): In our study, we consider reduction in carbon emissions as one of the enablers of the GSCM practices. In recent research scholars have investigated how an organization under the influence of institutional pressures may pursue various activities to reduce carbon emissions (Zhu and Sarkis; Wagner and Schaltegger; Schoenherr; Zhang and Wang). Zhu and Geng identified the drivers and barriers that come to the fore in the collaboration of Chinese manufacturers with their suppliers and customers to meet carbon emission goals. Chaabane et al. studied the trade-offs between economic and environmental goals under various strategies in the aluminium industry and called for better harmonization between current legislation and emission trading schemes in order for an environmental strategy to be realized. Zhang and Wang have looked into carbon emission reduction (CER) within industrial chains and have identified the lack of infrastructure as the main barrier that negatively influences inter-firm collaborations for CER. They also illustrated that CER impacts positively economic performance, but also relates to improved environmental performance [5].

Customer relationship management (CRM): Customers are becoming more educated and conscious about the environmental degradation and want the product they buy to be environment friendly. They may also want the final disposal and decomposition to be done without harming the environment. Customers in developed countries are more conscious on this issue than Indian customers. Hence the companies that export their products adhere more to adopting green practices in their supply chain as required by their customers. The recent research indicates that interface with customers provides valuable input, which helps to implement GSCM in an organization (Seuring et al.; Zhu et al.; Baines et al.). Zhu et al. discuss the capabilities of GSCM in Chinese firms between different contexts and call for greater collaboration between firms and customers for adoption of GSCM practices. In a recent study, Jayaram and Abittathur focused on the emerging economy of India and proposed a model that links environmental policies to customer actions and sustainability strategies. They found that managing customers in relation to green design, product recovery and reverse logistics are crucial for achieving GSCM. Hence, the management of customer relationships is an important enabler for GSCM implementation.

Increase in market share (MS): Increase in market share has been identified in the literature as one of the aims of GSCM (e.g. Gavronski et al.; Prajogo et al.; Pereira-Moliner et al.; Gunasekaran and Spalanzani). Hervani et al. pointed out how customer satisfaction resulting from GSCM practices may enhance loyalty feelings towards an organization, which in turn gets translated into an increase in market share as seen in many cases. Ahi and Searcy, in their review of definitions for green and sustainable supply chain management, suggest that GSCM is directly related with aims of firms to achieve greater market share, building on definitions by Zhu et al. and Buyukozkan and Cidci.

Increase in profitability (Profitability): The GSCM practices and increased focus on R's (i.e. reduction, reuse, reselling, repair, recycling, refurbishing, remanufacturing and reverse logistics) can help an organization achieve their bottom line (i.e. profitability) while at the same time the market share also increases due to enhanced customer satisfaction and green experience. The recent research further indicates that those organizations that have embraced GSCM as their corporate strategy have improved their bottom line (i.e. Gavronski et al.; Murovec et al.; Prajogo et al.; Pereira-Moliner et al.; Gunasekaran and Spalanzani; Dues et al. Zhu and Sarkis have related the adoption of green supply chain practices to performance, whereas in later studies this argument was further enhanced (Tate et al.; Hofer et al.).

In this section we discuss the attempts by scholars to build theory in GSCM.

Any attempt to build theory needs to answer fundamental questions (Sushil; Whetten), related to "what", "how" and "why" (Whetten). In this vein, studies suggesting frameworks as a way of advancing theory would need to provide answers regarding the basic constructs, dimensions or elements constituting the framework (what); hypothesized relationships among the research variables (how); and causal thinking (why) to explain the linkages among constructs that are envisaged as hypotheses. The questions of 'what', 'how' and 'why' may either be obtained from literature using past theories or models already validated by other researchers, or may be explored using grounded theory (Strauss and Corbin; Binder and Edwards; Soltani et al.) in areas where adequate conclusive literature is not available. The theory seeks the inputs from field in terms of qualitative views from working professionals/ experts based on their experience in the problem domain under investigation or by using case experiences in an inductive manner (Sushil; Strauss and Corbin). Researchers may find it easy to answer "what" either from literature or field or both so as to identify key variables as the starting point in any research query. They may use past theories to back "how" and "why". If however content analysis is used to identify elements or themes, answers to "how" and "why" are difficult to be provided in terms of relationships between elements and themes, and are usually portrayed on a case-to-case basis [6].

Drawing on the literature review from the previous section, we provide studies that propose a theoretical framework based on literature review and adopt statistical techniques or multiple criteria decision making (MCDM) tools or contextual method such as ISM or Graph Theory and

Matrix approach: Our literature review reveals that the majority of the papers do not aim to build but rather to test theoretical concepts through the use of quantitative methods. These frameworks do not provide a clear understanding related to linkages between, and hierarchical relationships among constructs. Furthermore, the majority of the studies do not combine quantitative and qualitative methods (mixed-methods) to build theory, but use already existing theory to explain why particular phenomena take place and they do not build new theory. Furthermore, in cases where theory building is attempted, apart from a few exceptions, scholars do not use mixed methods. There is research where theoretical frameworks have been developed using Interpretive structural modeling (ISM) (i.e. Thakkar et al.; Ali and Govindan; Luthra et al.; Mathiyazhagan et al.; Bag and Anand). However, even in hese cases, scholars do not attempt to 
synthesize ISM model and MICMAC output and do not empirically test the proposed models. To resolve these limitations and show the use of mixed methods for theory building in the context of GSCM, we will use ISM to develop a theoretical framework where we will consult experts and try to explore possible linkages among each construct enabler of GSCM (Table 1). ISM is a well-established methodology for identifying relationships among specific items/variables/factors that define a complex problem or an issue (e.g.Warfield; Sushil). It transforms poorly articulated complex models into visible and welldefined structural models showing the inter-relationships between the variables (e.g. Ali et al.; Attri et al.). Lastly it is amodeling technique as it extrapolates the specific relationships between variables and overall structure in a particular form. Scholars (e.g. Mandal and Deshmukh; Soti et al.; Ali andGovindan; Sushil) have outlined two limitations of ISM, that is, it usually involves a small sample size which may not be enough for statistica lreasons, and manager bias may influence the final ISM model. To deal with these limitations, we have further tested the ISM model using data collected through survey, and validate each construct of the model using confirmatory factor analyses (CFA) followed by regression analyses for hypothesis testing.

\section{Research Methodology}

Professionals from pharmaceutical company were working in the supply chain department was sampled in this research. An instrument for this purpose is being developed and used to conduct the survey. Survey is being carried out by conducting the interviews of those supply chain professionals. The purpose of this sampling was to choose those persons who have the knowledge about the topic and they know exactly what barriers are in the way of GSCM implementation. Number of respondents was 60 .

To evaluate this survey Exploratory Factor Analysis (EFA) and Confirmatory Factor Analysis (CFA) is used to explore the analysis.

The process of sampling which we used is non-probability sampling because every individual was not being sampled. Professionals from pharmaceutical company were working in the supply chain department was sampled in this research. An instrument for this purpose is being developed and used to conduct the survey. Survey is being carried out by conducting the interviews of those supply chain professionals. The purpose of this sampling was to choose those persons who have the knowledge about the topic and they know exactly what barriers are in the way of GSCM implementation. Number of respondents was 60 .

\section{Measurement}

To develop a measurement scale for the barriers in implementation of green supply chain management, we developed a list of 38 measurement items under six constructs namely, resources, awareness, training, TQEM, barriers, professionalism.

The targeted respondents are requested to indicate, using a five point likert scale. (1. Strongly agree, Agree, Neutral, Disagree, Strongly Disagree) the extent to which they perceived the barriers in

\begin{tabular}{|l|l|l|l|l|l|}
\hline \multicolumn{2}{|c|}{} & Frequency & Percent & Valid Percent & $\begin{array}{l}\text { Cumulative } \\
\text { Percent }\end{array}$ \\
\hline \multirow{6}{*}{ Valid } & Strongly agree & 18 & 30.0 & 30.0 & 30.0 \\
\cline { 2 - 6 } & agree & 28 & 46.7 & 46.7 & 76.7 \\
\cline { 2 - 6 } & neutral & 6 & 10.0 & 10.0 & 86.7 \\
\hline \multirow{2}{*}{ disagree } & 4 & 6.7 & 6.7 & 93.3 \\
\hline strongly disagree & 4 & 6.7 & 6.7 & 100.0 \\
\hline Total & 60 & 100.0 & 100.0 & \\
\hline
\end{tabular}

Table 1: Cost is a barrier for green supply chain.

\begin{tabular}{|l|l|l|l|l|l|}
\hline \multicolumn{2}{|c|}{} & Frequency & Percent & Valid Percent & $\begin{array}{l}\text { Cumulative } \\
\text { Percent }\end{array}$ \\
\hline \multirow{2}{*}{ Valid } & Strongly agree & 12 & 20.0 & 20.0 & 20.0 \\
\cline { 2 - 6 } & agree & 39 & 65.0 & 65.0 & 85.0 \\
\hline \multirow{2}{*}{ neutral } & 9 & 15.0 & 15.0 & 100.0 \\
\hline Total & 60 & 100.0 & 100.0 & \\
\hline
\end{tabular}

Table 2: Lack of corporate social responsibility.

\begin{tabular}{|l|l|l|l|l|l|}
\hline \multicolumn{2}{|l|}{} & Frequency & Percent & Valid Percent & $\begin{array}{l}\text { Cumulative } \\
\text { Percent }\end{array}$ \\
\hline \multirow{3}{*}{ Valid } & Strongly agree & 40 & 66.7 & 66.7 & 66.7 \\
\cline { 2 - 6 } & agree & 18 & 30.0 & 30.0 & 96.7 \\
\hline & neutral & 2 & 3.3 & 3.3 & 100.0 \\
\hline & Total & 60 & 100.0 & 100.0 & \\
\hline
\end{tabular}

Table 3: Due to the lack of internal audits within the organization.

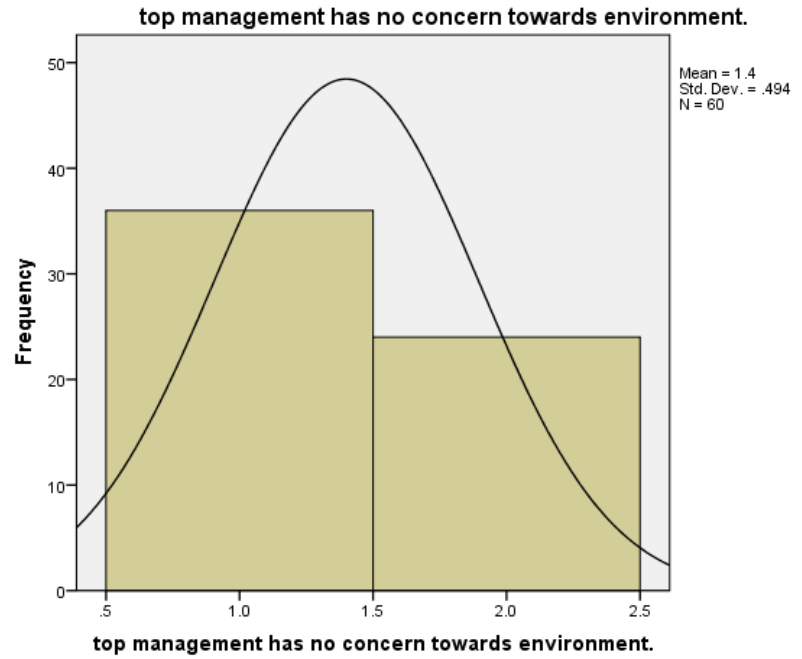

Figure 1: Management attitude towards environment.

implementation of green supply chain management in pharmaceutical companies

\section{Frequency table}

$76.7 \%$ of the respondents are agreed that the high cost is the barrier in the implementation of green supply chain management in pharmaceutical industries (Tables 1-3).

\section{Histogram}

It is used to analyze skewness their impact and their frequencies along with mean and standard deviation few figures are shown below (Figures 1 and 2).

Confirmatory Factor Analysis (CFA)

AMOS (Table 4)

\section{Interpretation}

This model is used for the significant we take the relative chi-value which is CMIN/DF in this table. If the value of CMIN is less than 3, the model is significant in this table the CMIN value is $2.686<3$, which means the model is significant. 


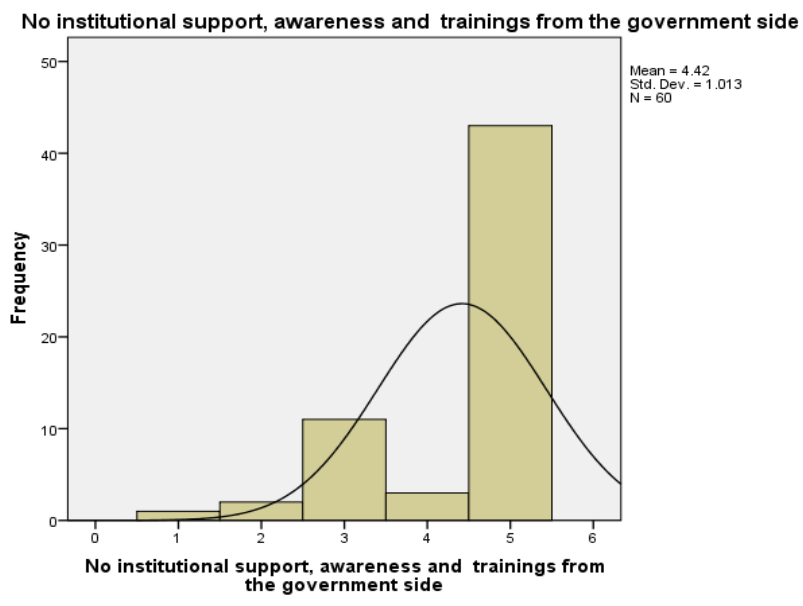

Figure 2: Institutional training programs.

\begin{tabular}{|l|c|c|c|c|c|}
\hline Model & NPAR & CMIN & DF & P & CMIN/DF \\
\hline Default model & 93 & 1638.709 & 610 & .000 & 2.686 \\
\hline Saturated model & 703 & .000 & 0 & & \\
\hline Independence model & 37 & 2074.761 & 666 & .000 & 3.115 \\
\hline \multicolumn{5}{r}{ Table 4: CMIN. }
\end{tabular}

\section{Discussion and Analysis}

The survey has been conducted in different pharmaceutical industries and data has been collected regarding the instrument. This has been shown from data that cost is the major barrier in the implementation of GSC. Cost is required in investment, training, for buying equipment. Cost is majorly acting as a barrier. Companies are reluctant to induct the green supply chain because they know that investment would be more but the return will be slow.

For the analysis of above survey we did EFA and CFA. Through EFA we checked the pattern matrix and performed different methods on SPSS to explore the validity of the instrument.

First we left on the SPSS to produce the factor and it produced 13 factors but they were doubling in the loading values. So, we decided to produce 8 factors than factor 6 and factor 8 became unloaded and the value on these factors was not loaded on factor 6 and 8 .

We produced 6 factors and then we produced CFA.

In EFA the most suitable pattern matrix we got from 6 factors, where there was the consistency in the loading values.

\section{Conclusion}

Through SPSS we knew the mean, mode and cumulative percent of the respondents answer on the survey. When we performed EFA and checked the pattern matrix of factors so we got double values on each variable so we reduced number of factors to 8 (Figure 3 ). Then we got better results because there wasn't any doubling but factor 5 and 8 was empty with no loaded value. We again reduced number of factors to 6 than we got better result and checked the average loading values but this average loading value was less than 0.7 so the convergent validity was failed and discriminant validity was also failed. The KaiserMeyer-Olkin measure of sampling adequacy is 0.464 , which showed that the number of respondents was in sufficient. We were able to get 60 respondents in the given time period. When we performed CFA

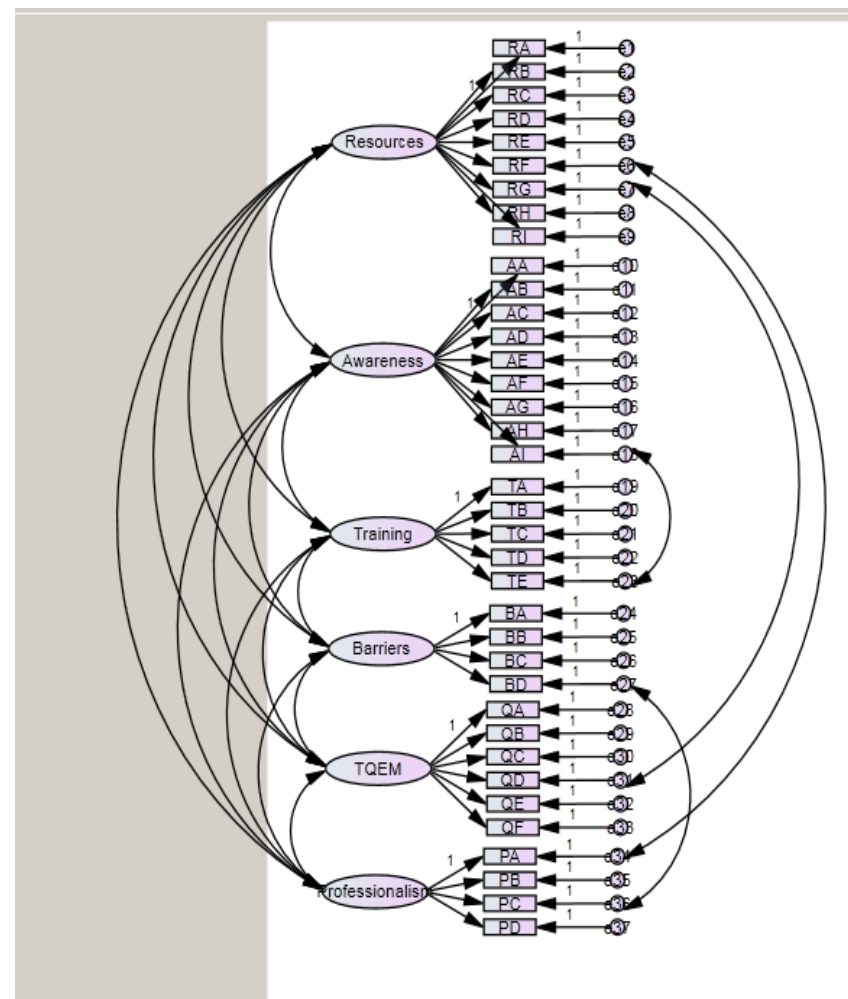

Figure 3: Co-relation is being determined in between variable in order to check their resemblances.

so except CMIN $\backslash$ DF all values were out. Value of CMIN $\backslash$ DF was less than 3. GFI and AGFI value was less than 0.85 and CFI value was less than 0.7. After the surveillance we find out the construct that they are applicable in the Karachi. The result shows that people were more prone towards eliminating barriers in green supply chain to maintain a healthy environment. They responded as they dwell in a busy scheduled life they found out that quality along with quality in medicine shall be increased keeping in view of environmental friendly conditions, in this city of Karachi, Pakistan. Through SPSS we knew the mean, mode and cumulative percent of the respondents answer on the survey.

\section{References}

1. Atasu A, Van Wassenhove LN, Sarvary M (2009) Efficient take-back legislation Prod Oper Manag 18: 243-258.

2. Guide VDR, Van Wassenhove LN (2001) Managing product returns for remanufacturing. Prod Oper Manag 10: 142-155.

3. http://www.interfaceglobal.com/company/history.aspx.

4. Reich-Weiser C, Vijayaraghavan A, Dornfeld D (2010) Appropriate use of green manufacturing frameworks. Proceedings of the CIRP life cycle engineering conference, China.

5. http://www.stonyfield.com/about-us.

6. Subramanian R, Gupta S, Talbot FB (2008) Product design and supply chain coordination under extended producer responsibility. Prod Oper Manag 18 259-277. 